\title{
Audit cycle on young people presenting with self-harm
}

\author{
Elaine Lockhart
}

\begin{abstract}
The first part of this audit looked at the demographics of young people presenting to Monklands Hospltal and the quality of their assessment. Precipltating factors and past psychiatric history were enquired of in the majortty of cases but there was a dearth of information regarding alcohol/drug use and family history. A checklist was devised with the aim of improving the quality of these assessments. The second part of the audit cycle completed one year later revealed considerable improvement in all categorles. It is hoped that this will be maintained by displaying the checklist in the accident and emergency department and continuing to include teaching about this vulnerable population to all new medical and nursing staff.
\end{abstract}

There has been much concern over the recent increase in teenage suicides and how to reduce this in line with the Health of the Nation targets. One-third of those who commit suicide will have made prior attempts and those who present with self-harm are at greatest risk of later suicide (Hawton \& Golacre, 1985; Shaffer \& Piacentini, 1994).

Over the past few decades there has been a marked increase in the number of referrals of young people with self-harm (Hawton \& Fagg, 1992). A large body of knowledge, although incomplete, has been collected to help clinicians detect those at greatest risk of further self-harm and completed suicide (Shaffer \& Piacentini, 1994).

These include: (a) males; (b) those with psychiatric disorders especially depressive illness and alcohol and substance misuse; (c) those from the lower socio-economic groups; and (d) those from a family with poor communication.

However, many young people who present with self-harm are neither psychiatrically disturbed nor suicidal and do not require psychiatric input. It is therefore essential that all these young people be adequately assessed by medical and nursing staff, in liaison with psychiatric services, taking cognisance of the known risk factors so that an informed decision can be taken regarding the need for psychiatric assessment or follow-up. As is policy in this hospital an interview with a social worker may be helpful prior to discharge.

\section{The study}

Monklands is a district general hospital in Lanarkshire serving a population of 166520 of whom 36783 are under 16 years. There is a psychiatric unit with two adult acute wards. The child psychiatrist is based at a clinic two miles away. A psychiatrist on call is resident in the hospital and sees all adult patients above school leaving age. Young people can be seen by the child psychiatrist if necessary on the ward or follow-up at the clinic can be arranged by the ward staff. The social work department aims to see all young people aged under 16 years who present with self-harm and they also offer a follow-up appointment after discharge.

The number of young people, those aged less than 18 years, presenting with self-harm to Monklands during the six months commencing 1 February 1995 was obtained from the accident and emergency (A\&E) department computerised records. Their A\&E cards and case notes, if admitted, were studied. Basic demographic features were obtained. The assessments carried out were studied looking in particular at: (a) enquiries regarding: precipitating factors, past psychiatric history, social history, alcohol/drug use, family history; (b) comment on the mental state.

Information was gathered from the medical and nursing notes and social work records regarding psychiatric and/or social work involvement. This process was repeated in 1996 covering the same six months.

\section{Findings}

In the first audit 44 young people presented during the six-month period of whom $31(70 \%)$ were female and $13(30 \%)$ male. All but three cases (93\%) presented having taken an overdose, two had selfinflicted lacerations and one had attempted to hang himself. Nearly three-quarters were admitted from $A \& E$. Of those discharged home $25 \%$ were seen by psychiatry and $17 \%$ by social work. The vast majority were asked about precipitating factors and past psychiatric history. However, in only onethird of cases was information documented regarding alcohol/drug use and less than one-tenth were 
asked about family history of either psychiatric or medical problems (Fig. 1).

\section{Action}

Following the completion of this audit the writer, while working with the local child and family team, met with the medical and nursing staff of the A\&E department, short-stay ward and relevant medical wards in addition to the senior social worker. There was widespread anxiety regarding the management of young people with self-harm and an eagerness to improve the service offered. It was agreed that a checklist would be placed in every $A \& E$ card whenever a young person presented with self-harm. This highlighted the relevant questions to be asked and the services available with the hope of facilitating fully informed decisions to be taken regarding the need for social work and/or psychiatric input.

\section{The repeat audit}

During the same six months in 1996, 23 young people presented with self-harm of whom 18 (78\%) were female and $5(22 \%)$ were male. Again the majority of cases $(87 \%)$ had overdosed. All but one were admitted from A\&E.

The quality of their assessment had improved in all areas with over $80 \%$ of cases having information about precipitating factors, past psychiatric history, their mental state and social history. Although improved there was still a lack of information regarding alcohol/drug use and family history in over $45 \%$ of cases (see Fig. 1).

\section{Comment}

The number of young people presenting with selfharm to Monklands Hospital is comparable to that found in previous studies and the female preponderance is typical. The relatively high admission rate (74 and 95\%) from $A \& E$ reflects the seriousness with which clinicians view self-harm in young people recognising that medically trivial overdoses may represent significant distress.

The quality of the first assessments demonstrates the pressurised nature of A\&E work and the emphasis on physical well-being by harried junior medical staff. Although precipitating factors and past psychiatric history were routinely enquired after, in the main little information was gained about the young person's home life, use of alcohol or drugs or family history. Without this information being passed on to senior medical staff an informed decision regarding the need for psychiatric assessment or followup cannot be safely made.

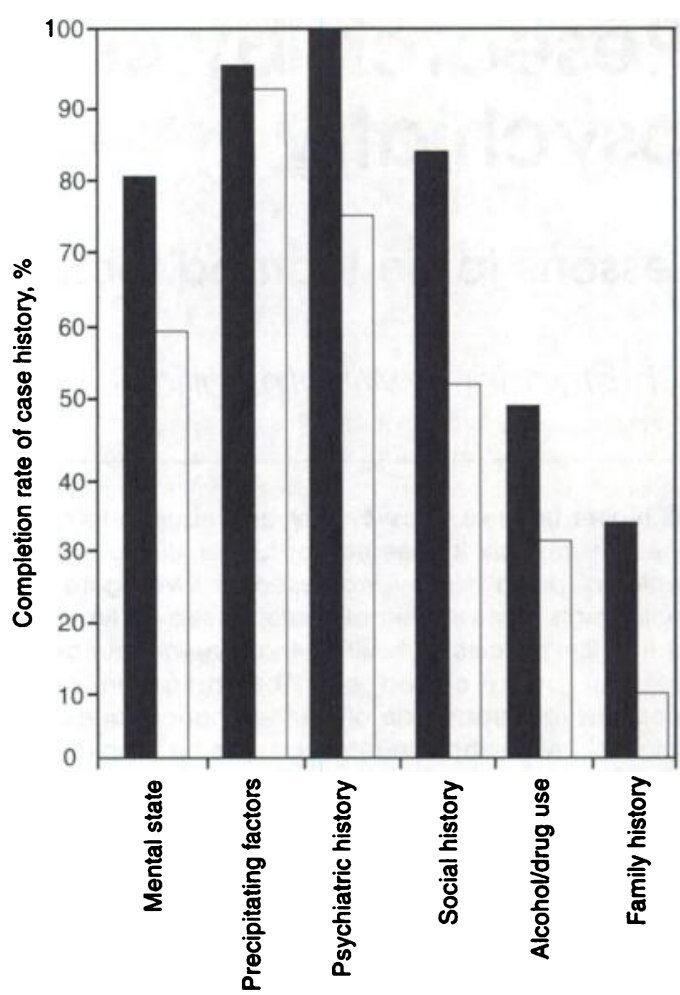

Fig. 1. Comparison of results between audit and re-audit. $\square$, audit; $\square$, re-audit.

However, as can be seen from the second audit the quality of assessments was improved significantly by raising staff's level of awareness of relevant risk factors and using a checklist to aid their assessment in a busy A\&E department.

On the basis of these results it was recommended that the checklist should be prominently displayed in the clinical rooms, and education regarding the assessment of young people with self-harm be included in the postgraduate teaching programme.

\section{References}

HAWTON, K. \& GOLACRE, M. (1985) Repetition of self-poisoning and subsequent death in adolescents who take overdoses. British Joumal of Psychiatry, 146, 395-398.

- \& FAGG, J. (1992). Deliberate self-poisoning and selfinjury in adolescents. A study of characteristics and trends in Oxford, 1976-89. British Journal of Psychiatry, 161, 816-823.

SHAFFER, D. \& PIACENTIN, J. (1994) Suicide and attempted suicide. In Child and Adolescent Psychiatry-Modern Approaches (eds M. Rutter, E. Taylor \& L. Hersov), pp. 407-417. Oxford: Blackwell Science.

Elaine Lockhart, Specialist Registrar, Department of Child Psychiatry, Caledonia House, Royal Hospital for Sick Children, Yorkhill, Glasgow G3 8SJ 